\title{
The Right to Write: Who 'Owns' the Case Report?
}

\author{
Akanksha Agrawal ${ }^{1}$, Dylan Eiger ${ }^{2}$, Deepanshu Jain ${ }^{3}$, Richard Allman ${ }^{1}$, Glenn Eiger $^{1}$ \\ ${ }^{1}$ Department of Internal Medicine, Einstein Medical Center, Philadelphia, PA, USA \\ ${ }^{2}$ Duke University, Durham, NC, USA
}

${ }^{3}$ Department of Digestive Diseases and Transplantation, Einstein Medical Center, Philadelphia, PA, USA

\section{Doi: 10.12890/2019_001005 - European Journal of Case Reports in Internal Medicine - ๑ EFIM 2019}

Received: $29 / 11 / 2018$

Accepted: 02/12/2018

Published: $16 / 01 / 2019$

How to cite this article: Agrawal A, Eiger D, Jain D, Allman R, Eiger G. The right to write: who "owns" the case report? EJCRIM 2019;6: doi:10.12890/2019_001005.

Conflicts of Interests: The Authors declare that there are no competing interests.

This article is licensed under a Commons Attribution Non-Commercial 4.0 License

Foreword of John Kellett, EJCRIM's Editor-in-Chief

In this Letter to the Editor, Agrawal et al. debate the conflicts that can arise regarding the authorship of case reports. Like all other medical journals, EJCRIM has zero tolerance for the willful undisclosed re-submission of papers that have already been published elsewhere. However, this may occasionally happen by accident, especially in large healthcare institutions in which multiple teams of physicians may care for a patient throughout their illness. EJCRIM endorses and recommends to all potential authors the very sensible suggestions made by Agrawal et al. to avoid such an error occurring. EJCRIM would also encourage authors to consider the following:

- The first author should ensure that no one else involved in the case has reported it or plans to report it. This is especially important for physicians working in large healthcare centres, and/or for case reports of patients who have been under investigation or treatment for prolonged periods.

- On rare occasions EJCRIM will consider a case that has already been published, provided that this is fully and explicitly disclosed, and there is a clear reason why re-publication is justified. An example might be where new information has come to light that significantly changes the conclusions of the original report. As in all reports published by EJCRIM the decision to publish will depend on the educational value, or learning points, of the case.

\section{LETTER TO THE EDITOR}

A 29-year-old woman presents to the emergency department (ED) with acute onset of aggressive behaviour. She is catatonic on examination. The ED resident thinks this is catatonic schizophrenia, but due to the presence of an acute kidney injury, the medicine service is called for advice on the admission. The medicine resident accompanied by a medical student performs a thorough history and examination. Several hours later, the patient becomes somnolent, develops acute hypoxic respiratory failure and is transferred to the medical intensive care unit (ICU). Due to a persistent catatonic state, neurology and psychiatry colleagues are consulted. A 24-hour electroencephalogram reveals an extreme delta brush spike pattern highly suggestive of anti-NMDA receptor encephalitis. Within hours, a computed tomogram (CT) of the abdomen and pelvis is performed showing a right ovarian teratoma. The patient undergoes urgent right salpingo-oophorectomy. The antiNMDA antibody is reported positive the following week. Supportive ICU care, corticosteroids, plasmapheresis and rituximab finally lead to significant neurological improvement and the patient is eventually transferred to a rehabilitation facility. 
The medical student is very excited about this patient: he has never seen NMDA encephalitis and wants to 'write it up'. The ED resident also follows up on the patient, and also thinks it is a 'great case' to write up. The medicine resident wonders if he can submit this case as an abstract for an upcoming national conference, while the neurology resident wants to present this case at a national neurology conference. Possible outcomes include simultaneous submission to multiple journals if the individual services do not communicate prior to submission, or conflict between multiple authors on a single case report.

This is an all too familiar situation; at our institution, conflicts have arisen over who might present or publish a case report. We are also aware of the same case being submitted independently for presentation and publication by different groups of authors without knowledge of other groups' submissions. This can result in unintentional misconduct with simultaneous, though inadvertent, submission to multiple journals or professional societies. What should be done to avoid such disputes? Should an institutional body oversee all submissions sent from a particular centre to avoid duplication, or perhaps the teams should discuss amongst themselves in deciding who made the diagnosis and who should be writing about it?

This brings us to our main question: who 'owns' this case report? We ask because it is unclear. Should an institutional research office or academic affairs office have a process for adjudicating these matters of 'ownership'? And if so, what standards should apply for such adjudication? Could a case with major teaching points in many disciplines be reported in more than one journal with a disclaimer that there are multiple medically unrelated issues? The answers to these questions are unclear, but intuitively, it is at the discretion of journal editors to make such a determination. Open disclosure at the time of submission is necessary to avoid academic fraud and concerns about plagiarism and simultaneous submissions.

Case reports are a valuable source of knowledge, advancing our understanding of rare diseases and their uncommon presentations. Osler observed: "Always note and record the unusual... Communicate or publish short note on anything that is striking or new"[1]. With the evolving practice of close interdisciplinary management of patients in order to provide the best possible care, many clinicians from different teams might have a claim of 'ownership' in reporting the same case from different perspectives. Recommendations have been published on how to write an excellent case report and where to publish it ${ }^{[2]}$. However, we were unable to find any articles that delineated the guidelines for claims of authorship of a case report.

In 2013, the CARE (CAse REport) guidelines were published with the objective of developing, disseminating and implementing systematic reporting guidelines for case reports. They were further elaborated in 2017 with implementation of a CARE checklist for writing and publishing case reports ${ }^{[3]}$. However, a challenge remains in deciding the authorship of case reports. We therefore gathered the perspectives of a medical student, resident, fellow and attending physician in order to formulate an approach on the authorship of case reports. Their opinions are as follows:

1. The number of authors for a case report should be limited to three to five, who should be the physicians directly involved with the case. Additional contributors to the case should be mentioned in the acknowledgements.

2. The primary (first) author should be the person who made the diagnosis, had direct patient contact, and wrote the largest share of the report. If that person is not interested in publishing, the case can be deferred to a peer who was also directly involved in the care of the patient.

3. The final author should be a senior author, typically an attending physician overseeing the care of the patient described in the case.

4. The second, third and fourth authors can include the student, resident and fellow, attending from any specialty services. All authors should meet the 'significant author contribution' requirements mentioned below.

5. 'Significant author contribution' requirements should meet all four of the following criteria as described by the International Committee of Medical Journal Editors (ICMJE) [4]:

- Substantial contributions to the conception or design of the work; or the acquisition, analysis, or interpretation of data for the work; AND

- Drafting the work or revising it critically for important intellectual content; AND

- $\quad$ Final approval of the version to be published; AND

- Agreement to be accountable for all aspects of the work in ensuring that questions related to the accuracy or integrity of any part of the work are appropriately investigated and resolved.

6. All case reports should be reported to the institution they are being submitted from. This will avoid duplicate submissions from the same institute. 


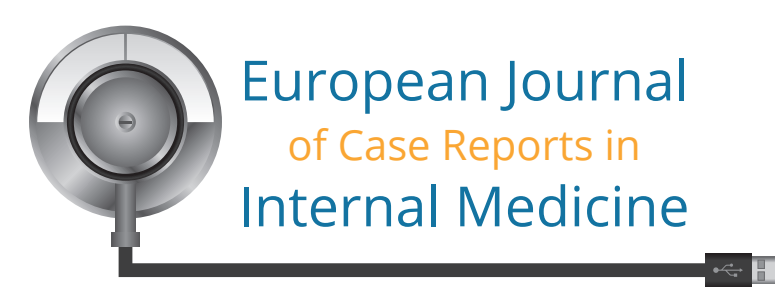

A recent New York Times article reiterated the role of the centuries-old art of case report writing ${ }^{[5]}$. Over the years, the medical literature has moved from "descriptive to mechanistic, from observational to explanatory and from anecdotal to statistical". However, case reports remain a great medical literature resource. They help in the professional development of physicians, enhancing their medical writing and presenting capabilities and scholarly activities. Our approach concerning authorship lacks strong evidence, as there is a scarcity of literature on this topic. However, we hope to generate discussion about conflicts regarding authorship for case reporting. We highlight the importance of concrete recommendations to guide authors in writing high-quality case reports to add to the ever-evolving medical literature with minimal conflict.

\section{REFERENCES}

1. Thomas HM. Sir William Osler, Bart. Baltimore, MD: The John Hopkins Press; 1920

2. Ortega-Loubon C, Culquichicon C, Correa R. The importance of writing and publishing case reports during medical training. Cureus 2017:9:e1964.

3. Riley DS, Barber MS, Kienle GS, Aronson JK, Schoen-Angerer TV, Tugwell P, et al. CARE guidelines for case reports: explanation and elaboration document. J Clin Epidemiol 2017;89:218-235.

4. International Committee of Medical Journal Editors (ICMJE). Recommendations for the conduct, reporting, editing, and publication of scholarly work in medical journals. Updated December 2017. Available from http://www.icmje.org/recommendations/ (accessed 7 Dec 2018).

5. Mukherjee S. What can odd, interesting medical case studies teach us? New York Times, 17 July 2018. Available from https://www.nytimes.com/2018/07/17/magazine/whatcan-odd-interesting-medical-case-studies-teach-us.html (accessed 7 Dec 2018). 